\title{
Amyotrophic Lateral Sclerosis: Interleukin-6 Levels in Cerebrospinal Fluid
}

\author{
Charles Krieger, Thomas L. Perry and Hermann J. Ziltener
}

\begin{abstract}
Recent observations indicate that antibodies to gangliosides are found in many patients with amyotrophic lateral sclerosis (ALS). If antigen-antibody complexes occur in ALS, elevations of cytokine levels might be expected, among them the cytokine interleukin-6 (IL-6). IL-6 is secreted by activated monocytes and other cell types and is an important mediator of the inflammatory response. We have measured cerebrospinal fluid (CSF) IL-6 levels in patients with ALS and compared them with those in psychiatric and neurodegenerative disorders not believed to be due to immune disorders of the central nervous system. We found no significant differences in CSF IL- 6 levels between these groups.
\end{abstract}

RÉSUMÉ: Sclérose latérale amyotrophique: niveaux d'interleukine-6 dans le liquide céphalo-rachidien. Des observations récentes indiquent qu'on retrouve des anticorps dirigés contre les gangliosides chez plusieurs patients atteints de sclérose latérale amyotrophique (SLA). S'il existe des complexes antigène-anticorps dans la SLA, on peut s'attendre à une élévation des niveaux de cytokines, dont l'interleukine-6 (IL-6). L'IL-6 est sécrétée par les monocytes activés et d'autres types de cellules et est un médiateur important de la réponse inflammatoire. Nous avons mesuré les niveaux d'IL-6 dans le liquide céphalo-rachidien (LCR) chez des patients atteints de SLA et nous avons comparé ces niveaux à ceux de patients atteints de maladies psychiatriques et neurodégénératives qu'on ne croit pas être dues à une affection immunitaire du système nerveux central. Nous n'avons pas trouvé de différence significative dans les niveaux d'IL-6 dans le LCR entre ces groupes.

Can. J. Neurol. Sci. 1992; 19:357-359

Amyotrophic lateral sclerosis (ALS) is a progressive degenerative disorder of motoneurons and corticospinal tracts of unknown etiology. The possibility that an autoimmune mechanism might be responsible for ALS has been investigated; however, many features of conventional autoimmune disorders are absent.' Recent observations indicate that many ALS patients have serum antibodies to $\mathrm{GM}_{1}$ gangliosides. ${ }^{2.3}$ In addition, antibodies to $\mathrm{GD}_{1 \mathrm{u}}, \mathrm{GD}_{1 \mathrm{~b}}$ and asialo-GM, gangliosides have been reported to be present in some patients with motor neuron disease. ${ }^{3-5}$ Gangliosides are found in high concentration on neuronal membranes, and antibodies to gangliosides may be pathogenic. ${ }^{2.5}$

In the event that antigen-antibody complexes occur in ALS, a variety of tissue responses is expected, including increased levels of cytokines such as interleukin-6 (IL-6; interferon- $\beta 2$ ). ${ }^{6}$ IL6 is a multifunctional cytokine having numerous biological effects including: B lymphocyte differentiation and stimulation of $\operatorname{lgG}$ secretion, growth stimulation of hybridomas and plasmacytomas, T lymphocyte activation, stimulation of hematopoeisis, induction of hepatic acute phase proteins and other effects. ${ }^{7}$ IL-6 does not possess neurotrophic activity for cholinergic neurons in rodent brain ${ }^{8}$ or avian motoneurons in culture. ${ }^{9}$ The induction of IL-6 in man is incompletely understood. However, it seems clear that IL-6 will increase in body fluids in response to viral and bacterial infections ${ }^{10}$ as well as inflammatory diseases such as rheumatoid arthritis. ${ }^{\prime \prime}$

To evaluate the possible involvement of IL-6 in ALS we have examined cerebrospinal fluid (CSF) IL-6 levels in ALS patients and compared them to those in subjects with psychiatric and neurodegenerative disorders.

\section{Materials ANd Methods}

\section{Patients and Controls}

CSF was obtained with informed consent from 15 patients with ALS and from 20 control subjects: 9 patients with psychiatric disorders (unipolar and bipolar affective disorders and schizophrenia) and 11 patients with neurodegenerative diseases (Parkinson's disease, spinocerebellar degeneration and spastic paraparesis). CSF specimens were also obtained from 3 patients having inflammatory nervous system diseases expected to increase CSF IL-6 levels and these samples served as positive

From the Division of Neurology, Department of Medicine (C.K.); Department of Pharmacology and Therapeutics (T.L.P., deceased); The Biomedical Research Centre (H.J.Z.), The University of British Columbia, Vancouver, British Columbia, Canada V6T 2B5

Received January 7, 1992. Accepted February 6, 1992

Reprint requests to: Dr. C. Krieger, Division of Neurology, Department of Medicine, University Hospital, U.B.C. site, 2211 Wesbrook Mall, Vancouver, British Columbia, Canada V6T 2B5 
controls (aseptic meningitis, post-EBV cerebellitis and cerebrothromboembolic disease). ALS patients fulfilled all the following criteria: 1) upper and lower motor neuron signs, or lower motor neuron signs only, commencing focally and showing a progressive asymmetrical spread without sensory symptoms or signs. 2) Normal computerized tomography, myelography or magnetic resonance imaging studies. 3) Electromyographic evidence of acute and chronic denervation involving limb and axial musculature with normal nerve conduction velocities. 4) No evidence of heavy metal intoxication or endocrine abnormalities. Patients and controls were well at the time CSF was obtained except for their nervous system disorders and had no evidence of infection. CSF specimens used for analysis were obtained at LP, frozen immediately on dry ice and were subsequently stored at $-70^{\circ} \mathrm{C}$ until assayed.

\section{Assay for IL-6 activity}

IL-6 activity was measured by $\left({ }^{3} \mathrm{H}\right)$ thymidine incorporation of the murine hybridoma subclone $B 9^{12}$ which is responsive to human as well as murine IL-6. CSF samples were serially diluted, incubated with $500 \mathrm{~B} 9$ cells in a $10 \mu \mathrm{l}$ volume in Terasaki trays for 72 hours and a 6 hour pulse of $0.25 \mu \mathrm{Ci}$ of $\left({ }^{3} \mathrm{H}\right)$ thymidine was given. One unit of IL- 6 bioactivity was defined as the amount of IL- $6 / \mathrm{ml}$ that induced $50 \%$ of maximal proliferation.

To characterize the IL-6-like activity, neutralizing polyclonal antibodies were raised against human IL-6. IL-6 was synthesized by solid phase peptide synthesis (the generous gift of Dr. I. Clark-Lewis) as previously described for IL-3. ${ }^{13}$ IL-6 was emulsified in complete Freund's adjuvant and injected subcutaneously into rabbits followed by 3 booster injections at 3 weekly intervals of synthetic IL-6 emulsified in incomplete Freund's adjuvant.

\section{RESULTS}

The specificity of the B9 bioassay for IL-6 is shown in Figure 1 which demonstrates 2 typical examples of titration curves of CSF from ALS patients (open symbols). This IL-6 bioactivity was completely neutralized by addition of antihuman IL-6 antibodies to each sample (filled symbols).

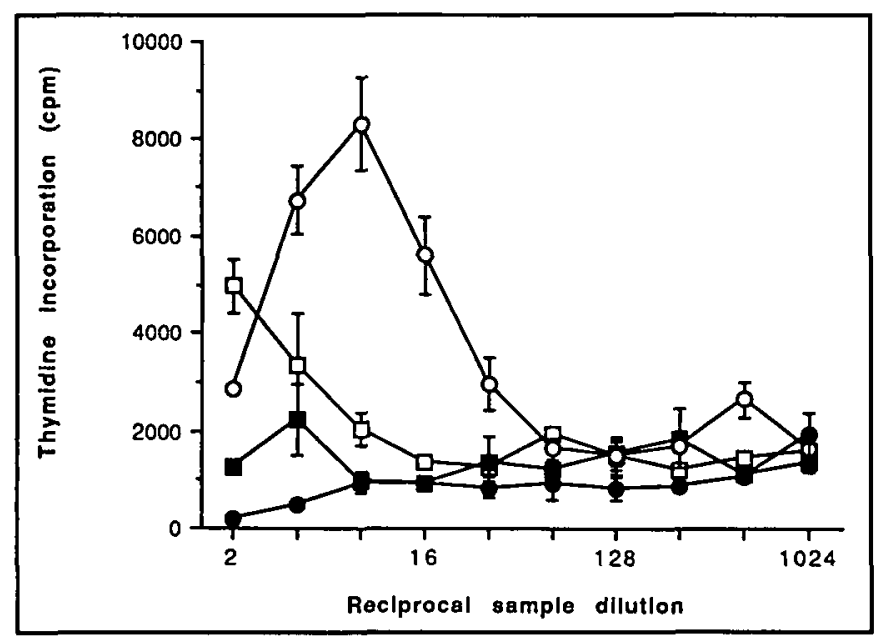

Figure I - Thymidine incorporation of the IL-6-responsive B9 cell line against sample dilution for 2 CSF samples from ALS patients (open symbols). Closed symbols indicate corresponding points in the presence of anti-human IL-6 antibody.
Figure 2 shows the IL-6 bioactivities for patients with ALS, psychiatric (PSY) and neurodegenerative disorders (DEG). With the exception of 6 samples (lowest points in each group) IL-6 bioactivity was present in detectable amounts in all CSF samples. The mean CSF IL-6 concentrations for the 3 groups were (mean \pm s.d. in Units/ml): ALS $1.6 \pm 1.9(n=15)$, PSY $2.7 \pm 5.0$ $(n=9)$, DEG $2.9 \pm 5.2(n=11)$. The 3 positive controls had a mean IL-6 level of $341.3 \mathrm{U} / \mathrm{ml}$. IL-6 bioactivity in ALS, PSY and DEG demonstrated no statistically significant differences (Mann-Whitney 2 tailed test, 0.05 confidence limits). In only 1 of the ALS patients was the CSF IL-6 concentration more than 3 S.D. greater than the mean for the ALS group. This patient was not unusual in clinical course, duration or severity of illness.

\section{Discussion}

We have employed a bioassay using the proliferative response of the IL-6-responsive B9 hybridoma line to measure IL-6 levels in the CSF of patients with ALS, psychiatric and neurodegenerative disorders. The bioassay used here was sufficiently sensitive to detect IL-6 activity at concentrations greater than $0.2 \mathrm{U} / \mathrm{ml}$, and most CSF samples had detectable levels of IL-6. IL- 6 activity which was detected with the B9 hybridoma assay could be neutralized by antibodies specific for human IL- 6 demonstrating that it was due to human IL-6.

CSF IL-6 is known to be elevated in patients with acute bacterial or viral meningitis and encephalitis. ${ }^{10}$ IL- 6 may also be increased in CSF from patients with primary or metastatic neoplasms of the nervous system and in multiple sclerosis. ${ }^{14}$ Possible sources of CSF IL-6 are T lymphocytes, monocytes and glial cells, likely microglia and astrocytes. ${ }^{12.15}$

Antibodies to gangliosides have been observed frequently in the sera of patients with ALS. If such antibodies formed antigenantibody complexes they might induce the production of IL-6. ${ }^{6}$ We compared CSF IL-6 levels in patients with ALS and those having psychiatric and neurodegenerative disorders believed not to be due to immune dysfunction of the central nervous system.

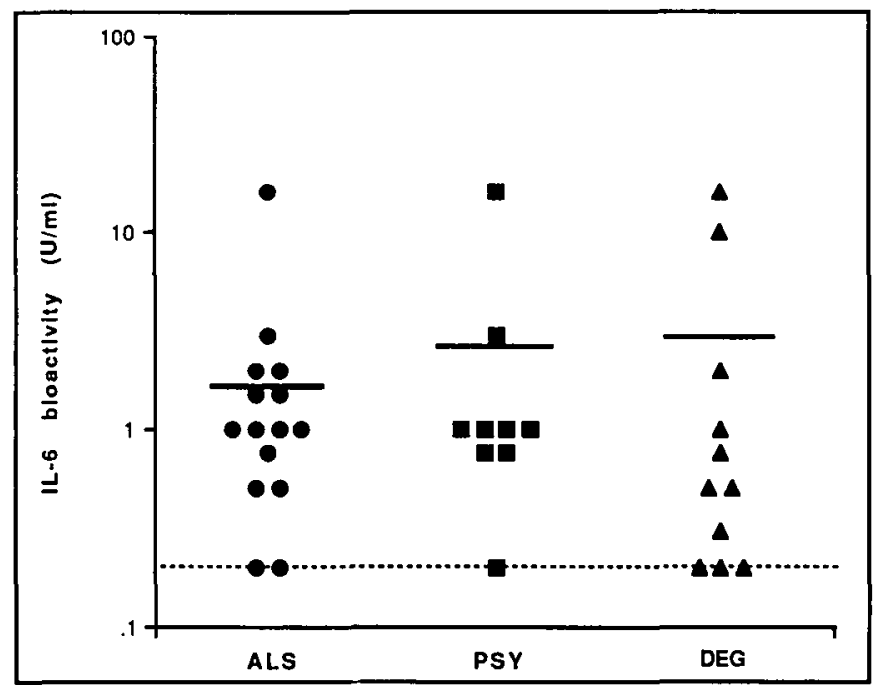

Figure 2 - IL-6 bioactivity in ALS, psychiatric disorders (PSY), and neurodegenerative disorders $(D E G)$ in Units/ml. Interrupted line indicates the limits of detectability of IL-6. 
No statistically significant differences in CSF IL-6 levels were observed in these patient groups. Our results do not indicate a role for IL-6 in the pathogenesis of ALS.

\section{ACKNOWLEDGEMENTS}

Supported by the Canadian MRC, BCHCRF, The Biomedical Research Centre and STDF of B.C. We would like to thank Ms. M. Rebbetoy and Mrs. S. Hansen for assistance.

\section{REFERENCES}

1. Drachman DB, Kuncl RW. Amyotrophic lateral sclerosis: an unconventional autoimmune disease? Ann Neurol 1989; 26: 269-274.

2. Pestronk A, Adams RN, Clawson L, et al. Serum antibodies to

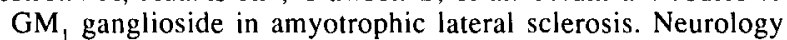
1988; 38: 1457-1461.

3. Shy ME, Evans VA, Lublin FD, et al. Antibodies to GM, and GD in patients with motor neuron disease without plasma cell dyscrasia. Ann Neurol 1989; 25: 511-513.

4. Pestronk A, Adams RN, Cornblath D, et al. Patterns of serum IgM antibodies to $\mathrm{GM}_{1}$ and $\mathrm{GD}_{1 \mathrm{a}}$ gangliosides in amyotrophic lateral sclerosis. Ann Neurol 1989; 25: 98-102.

5. Latov N, Hays AP, Donofrio PD, et al. Monoclonal IgM with unique specificity to gangliosides $\mathrm{GM}_{1}$ and $\mathrm{GD}_{1 \mathrm{~b}}$ and to lacto-Ntetraose associated with human motor neuron disease. Neurology $1988 ; 38: 763-768$
6. Ling Z-D, Ziltener HJ, Webb BT, et al. Aggregated immunoglobulin and $\mathrm{Fc}$ fragment of IgG induce IL-6 release from human monocytes. Cell Immunol (in press).

7. Wong GG, Clark SC. Multiple actions of interleukin 6 within a cytokine network. Immunol Today 1988; 9: 137-139.

8. Kamegai M, Niijima K, Kunishita T, et al. Interleukin 3 as a trophic factor for central cholinergic neurons in vitro and in vivo. Neuron 1990; 2: 429-436.

9. Arakawa $Y$, Sendtner $M$, Thoenen $H$. Survival effect of ciliary neurotrophic factor (CNTF) on chick embryonic motoneurons in culture: comparison with other embryonic factors and cytokines. J Neurosci 1990; 10: 3507-3515.

10. Houssiau FA, Bukasa K, Sindic CJM, et al. Elevated levels of the $26 \mathrm{~K}$ human hybridoma growth factor (interleukin 6) in cerebrospinal fluid of patients with acute infection of the central nervous system. Clin Exp Immunol 1988; 71: 320-323.

11. Guerne P-A, Zuraw BL, Vaughan JH, et al. Synovium as a source of interleukin 6 in vitro. J Clin Invest 1989; 83: 585-592.

12. Aarden LA, De Groot ER, Schaap OL, et al. Production of hybridoma growth factor by human monocytes. Eur J Immunol 1987; 17: 1411-1416.

13. Clark-Lewis IR, Aebersold R, Ziltener HJ, et al. Automated chemical synthesis of a protein growth factor for hemopoetic cells Interleukin-3. Science 1986; 231: 134-139.

14. Leppen D, Frei K, Gallo P, et al. Brain tumors: detection of B-cell stimulatory factor- $2 /$ interleukin- 6 in the absence of oligoclonal bands of immunoglobulins. J Neuroimmunol 1989; 24: 259-264.

15. Frei K, Malipiero UV, Leist TP, et al. On the cellular source and function of interleukin 6 produced in the central nervous system in viral diseases. Eur J Immunol 1989; 19: 689-694. 